\title{
Chapter 9 \\ The Transition of Radiocesium in Peach Trees After the Fukushima Nuclear Accident
}

\section{Daisuke Takata}

\begin{abstract}
In this chapter, we introduce the effects of radiocesium released by the Fukushima Daiichi nuclear accident on fruit trees, especially the change of radiocesium in fruit during the past 6 years. We investigated radiocesium and ${ }^{40} \mathrm{~K}$ in peach during the maturity of its fruit chronologically for 6 years. In the investigation during one crop period, the concentration of radiocesium in young fruit 15 days after the full bloom was the highest, and this result was common in all the investigated years. After that, the concentration of radiocesium decreased as the fruit became bigger; the decrease until 60 days after the full bloom was considerable. This tendency was also common among all investigations conducted until 2016. Though the concentration of ${ }^{40} \mathrm{~K}$ during the same period also decreased in the same way as radiocesium, the rate of the decrease from 15 to 30 days after the full bloom was different. When looking at the chronological transition, the concentration of radiocesium in harvested fruit decreased by one third every year from 2011 to 2013. However, such decrease could not be seen from 2014 to 2016 . While the concentration in the harvested fruit tended to stop decreasing, the concentration in fruit 15 days after the full bloom tended to decrease over the years from 2012 to 2016. During the past 6 years, there was no year-over-year decrease in the concentration of ${ }^{40} \mathrm{~K}$ in fruit. The reason why the transition of radiocesium in fruit varied according to their stage of maturity was because the difference in timing to use the tree's nutrient reserves.

To understand the year-over-year transition of radiocesium in peach, the amount of ${ }^{137} \mathrm{Cs}$ in every part of the tree was measured. When comparing the distribution of ${ }^{137} \mathrm{Cs}$ and ${ }^{40} \mathrm{~K}$ in the peach trees, it was found that ${ }^{137} \mathrm{Cs}$ was existing in the body of the tree, which was contaminated by fallout, while ${ }^{40} \mathrm{~K}$ was distributed more in the leaves and fruit. Also, while the weight of the trees and the amount of ${ }^{40} \mathrm{~K}$ in the tree body increased with time, the amount of ${ }^{137} \mathrm{Cs}$ decreased over the years. It is considered that radiocesium stored in the mature woody parts such as stem and branches had been transferred to fruit, leaves, or young branches.
\end{abstract}

\section{Takata $(\bowtie)$}

Faculty of Food and Agricultural Sciences, Fukushima University, Fukushima, Japan

e-mail: r841@ipc.fukushima-u.ac.jp 
Keywords Peach $\cdot$ Cs $\cdot$ Fruit tree $\cdot$ Fukushima Daiichi Nuclear Power Plant accident

\subsection{Introduction}

Fukushima Prefecture has 6820 ha of orchards in 2016 and it is one of the top fruit producing areas in Japan (National Statistics Center 2016). When looking at each kind of fruit, the area of the land under cultivation with peaches is the second largest in Japan (1810 ha), and this means that the prefecture is one of the major producers of fruit in Japan even after the Fukushima Daiichi nuclear accident. With regards to changes to the retail price of fruit, Komatsu (2014) and the author's previous study (Takata 2016), show that most fruits have returned to their pre-accident prices, yet the situation is not the same as before.

Six years after the accident, the concentration of ${ }^{134} \mathrm{Cs}$ is thought to be in low in fruit because its half-life is about 2 years. On the other hand, ${ }^{137} \mathrm{Cs}$, whose half-life is longer than ${ }^{134} \mathrm{Cs}$ can still be detected. However, previous studies found that radiocesium in fruit decreased more quickly than its actual half-life; for example, the concentration of ${ }^{137} \mathrm{Cs}$ decreased by one third in the second year, and by another one third in the third year after the accident (Takata et al. 2014, 2016). These results correspond to what was found in several types of fruit after the Chernobyl nuclear power plant accident (Antonopoulos-Domis et al. 1990; Madoz-Escande et al. 2004). However, there are few reports which traced and investigated products in the same region to examine a long-term transition of the concentration of radiocesium in fruit trees, and the future transition is uncertain. To understand this point, it is necessary to investigate the concentration of radiocesium not only in fruit continuously but also in trees which are the source of Cs in fruit. The author's previous study found that radiocesium in soil has almost no relationship with Cs in fruit in most cases. This is because (1) the radiocesium transfer factor (TF) ratio for fruit is lower than annual crops in Japan, (2) trees are no longer affected by fallout which fell directly on bark, and largely contributed to the concentration of radiocesium in the fruit (Takata et al. 2012b, 2013a), (3) since radiocesium in the trees remain in situ year after year, this has become a source of radiocesium in fruit (Takata et al. 2012d, 2013c), and (4) most kinds of fruit in Fukushima Prefecture (except a few kinds such as blueberries) do not form their rooting zones within $5 \mathrm{~cm}$ from surface horizon and thus they do not absorb radiocesium, which was distributed only on the surface horizon unevenly (Takata et al. 2013b). The fourth reason is also related to the fact that potassium fertilizer has no effect in most cases. Therefore, it is necessary to investigate trees continuously to understand the source of radiocesium in fruit.

In this chapter, new research findings, after the author's previous two reports stated above, are reported. Especially, understanding the dynamics of radiocesium in fruit and redistribution of ${ }^{137} \mathrm{Cs}$ in trees 6 years after the accident is the focus. 


\subsection{The Year-Over-Year Transition of Radiocesium in Fruit}

After the nuclear power plant accident, one variety of peach "Akatsuki" was investigated continuously regarding the concentration of radiocesium in the fruit in Shimooguni district, Ryozen-machi, Date City from harvest in 2001 to 2016. In 2011, the concentration of radiocesium in the harvested fruit was measured. From 2012 to 2016, the concentration of radiocesium and ${ }^{40} \mathrm{~K}$ was measured throughout fruit development: from Day 15 after the full bloom to harvest (approximately Day 103).

Figure 9.1 shows the transition of radiocesium (calculated using dry mass) in peach fruit. The red arrows indicate the concentration in the harvested fruit. As shown in the author's previous research, the concentration decreased approximately by one third from 2011 to 2012. It also decreased by one third from 2012 to 2013. Though it was expected that the year-over-year decrease would continue in the same way, the concentration in the fruits in 2014 showed a slightly higher value than the level in the prior year. In 2015 and 2016, the concentration of radiocesium in the harvested fruit decreased slightly, but this decrease was not significant, and the transition after 2013 tended to be a gradual decrease or almost no change. This fact has both good and concerning aspects. The positive aspect is that it is possible to continue to produce fruit without concerns when the concentration of radiocesium is lower than the current standard value of $100 \mathrm{~Bq} / \mathrm{FW}$. It is expected that fruit will not require dedicated countermeasures, whereas some other crops such as rice needs continuous countermeasures (e.g., application of potassium fertilizer) to lower the radiocesium concentration. Applying potassium fertilizer and absorption of radiocesium from soil will not be elaborated on in this chapter because it has already been covered in the author's previous articles. On the other hand, the concerning points are regional problems and issues related to sales methods. Regional problems refer to the fruit production in regions showing a high concentration of radionuclides, such as Hama-dori region. Hama-dori region represented by Namie-machi is famous

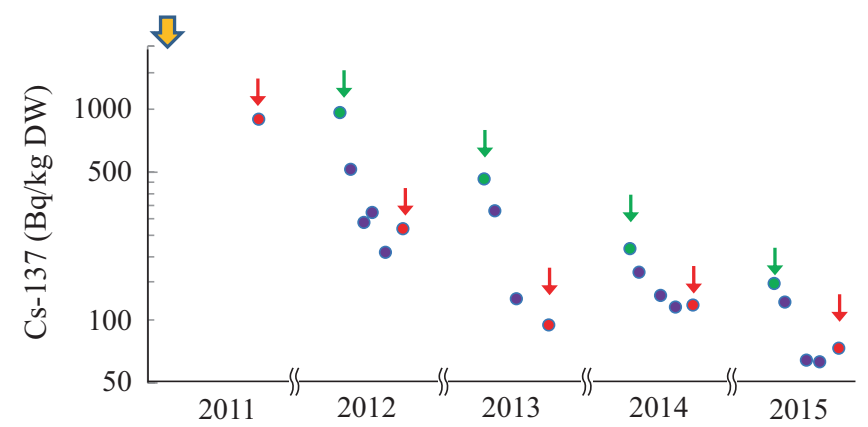

Fig. 9.1 Seasonal change of ${ }^{137} \mathrm{Cs}$ concentration in peach fruit from 2011 to 2016 . The pink bars indicate the period of peach fruit growth from full bloom to harvest. The yellow arrow indicates the time of the accident (i.e., March 2011). The green dots indicate the young peach fruits 15 days after full bloom. The red dots indicate the peach fruits at harvest time. The purple dots are the peach fruits between youngest fruits and harvested fruits 
for Asian pear production, and the findings presented above does not instill confidence to resume production there. Yet, it is unrealistic to reuse the same trees to resume fruit production in these regions because the trees have gone without pruning and pest control, and the trellis are likely to have deteriorated. Also, the soils were contaminated with a large amount of radionuclides and it would be necessary to replace the soil and to plant new trees. Therefore, the data shown in this study has no negative effect on fruit production, and what should be considered first is not issues of cultivation but financial aspects such as compensation for farmers during the time without income, the replacement and planting of new trees, and decontamination of surface soil. On the other hand, Japanese persimmon produced mainly in Date City can carry with it a severe problem because of how this fruit is sold. In Date City, persimmons are processed and sold as Anpo-gaki. It is a kind of Hoshigaki (dried persimmon) and the fruits are semi-dried. In Japan, because a standard value of radiocesium is determined in products at the point of sale, the radiocesium concentration is measured in the dried persimmon to compare it with the standard value $(100 \mathrm{~Bq} / \mathrm{kg})$. Therefore, we need to be careful in producing raw materials for dried persimmon because radiocesium in persimmon is concentrated after drying. Although, Anpo-gaki started to be sold again in 2013, it is necessary for producers whose fruits show radiocesium concentrations close to the standard value to carry out drastic measures such as replanting to ensure the concentration in the fruit is below the standard value. The green arrows in Fig. 9.1 show the concentration of radiocesium in fruit 15 days after the full bloom. It has been decreasing year-overyear until 2016, while the concentration at the time of harvest stopped decreasing. The concentration of radiocesium in trees may contribute to the different trends between 15-day-old fruit and harvested fruit. Young organs in peach trees grow using their nutrient reserves for 3-4 weeks after flowering, and inadvertently this results in the transfer of radiocesium to young organs. Young fruit show high a concentration of radiocesium because they rely on the tree's nutrient reserves. As the fruit matures and nutrients in the soil contribute more, the radiocesium concentration is believed to decrease. The decrease of the concentration following maturity of fruits is common with the transition of ${ }^{40} \mathrm{~K}$ in fruits shown in Fig. 9.2. Though the ratio of the transition is different between these two elements, they show a similar tendency. On the other hand, the year-over-year transition of ${ }^{40} \mathrm{~K}$ could not be seen. This may be because the source of ${ }^{40} \mathrm{~K}$ and ${ }^{137} \mathrm{Cs}$ transferred into fruit is different.

\subsection{The Year-Over-Year Transition of Radiocesium in Trees}

Radiocesium was detected mainly in organs exposed to the atmosphere such as bark, because fruits trees are perennial plants and grew in the fields even at the time of the accident (in winter) (Takata et al. 2012a, d). Of course, fruit also absorb radiocesium from the soil through their roots, but it has already been confirmed that when considering the source of $\mathrm{Cs}$ in fruit, the ratio of radiocesium due to the fallout that adhered to the bark and was transferred to fruits is much higher than absorption through the 


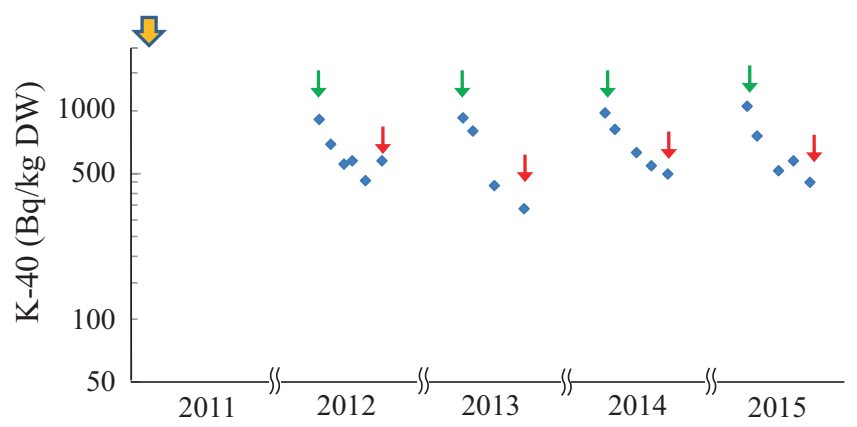

Fig. 9.2 Seasonal change of ${ }^{40} \mathrm{~K}$ concentration in peach fruit from 2011 to 2016 . The pink bar indicates the period of peach fruit growth from full bloom to harvest. The yellow arrow indicates the time of accident (i.e., March 2011. The green arrows indicate the young peach fruits 15 days after full bloom. The red arrows indicate the peach fruits at harvest time. The blue dots indicate the peach fruits between the youngest fruits and harvested fruits

roots. Therefore, it is important to grasp the transition of the concentration of radiocesium not only in the soil but also in the trees to understand the concentration in fruits. As stated in an earlier section, the concentration of radiocesium in peach fruit decreased as they matured and decreased over 3 years after the accident. It is important to understand the amount of radiocesium in trees to consider the cause of rapid decrease of the concentration over the 3 years after the accident; there is no report which investigated the amount of radiocesium in trees year-over-year. We introduce a study (Takata et al. 2016) which dug up trees after leaf fall to investigate the distribution of ${ }^{137} \mathrm{Cs}$ and compare the dynamic of ${ }^{137} \mathrm{Cs}$ in trees with that of ${ }^{40} \mathrm{~K}$.

We used another variety of peach "Yuzora" planted in the fruit research center of Fukushima Agricultural Technology Center. The individual parts of peach trees of a similar age and planted in the same year were separated for the investigation from 2012 to 2014. Stems and branches were collected, and the branches were sorted according to their age. The roots were collected and sorted according to their thickness. The concentration of ${ }^{137} \mathrm{Cs}$ and ${ }^{40} \mathrm{~K}$ in each part were measured and calculated using the dry mass of each part to convert the measured values into the quantities (expressed by $\mathrm{Bq}$ ) of each organ.

Figure 9.3 shows that the weight of the trees increased year-over-year. The concentration of ${ }^{137} \mathrm{Cs}$ in the soil was the highest in the surface horizon $(0-3 \mathrm{~cm})$ and decreased in the deeper horizons. This result corresponded to the investigation in orchards in Fukushima after the nuclear power plant accident (Takata et al. 2012c). On the other hand, the concentration of ${ }^{40} \mathrm{~K}$ in the soil was almost the same across all horizons depths. Figures 9.4a and 9.5a shows that the amount of ${ }^{137} \mathrm{Cs}$ and ${ }^{40} \mathrm{~K}$, respectively, in each organ calculated by multiplying the weight of each organ and the concentration of the radionuclides together; Figs. 9.4b and 9.5b shows the distribution which converts the whole amount of the radionuclides during each crop period into 100. The distribution of ${ }^{137} \mathrm{Cs}$ in trees after 10 months, which is equivalent to one crop period was almost similar with what was reported for peach trees 


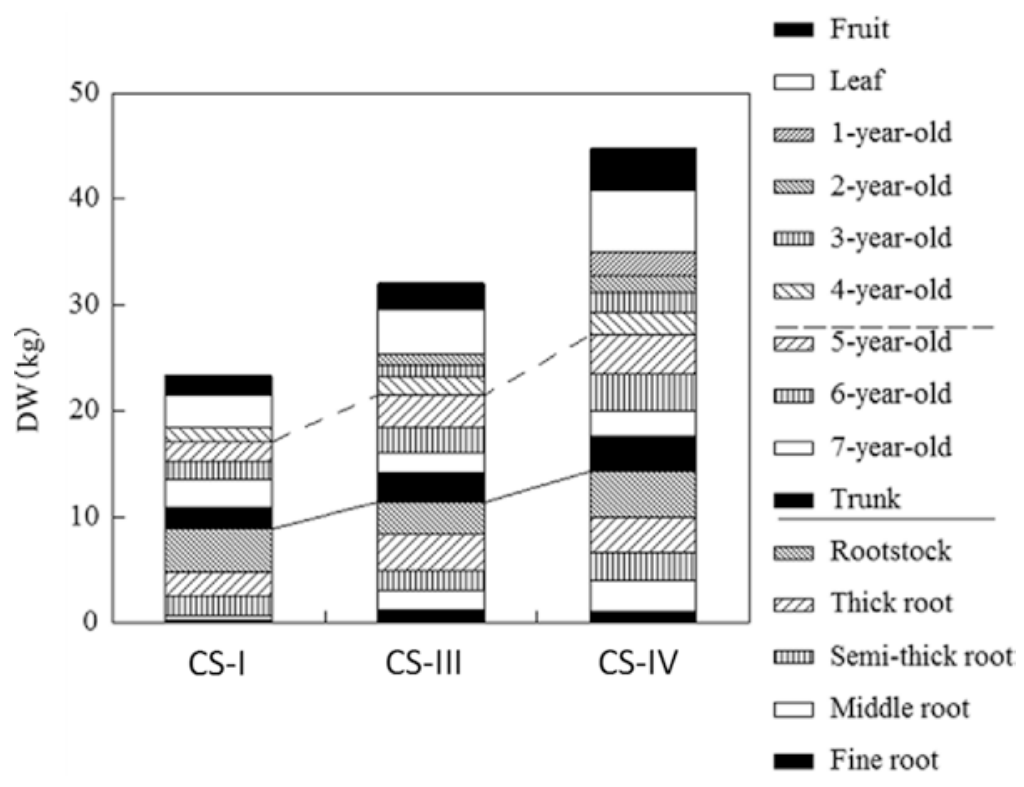

Fig. 9.3 Annual changes in dry-weight of peach trees after the Fukushima Daiichi Nuclear Power Plant Accident (Takata 2016. CS: Cropping season after FDNPP accident, CS-I: 2011 summer, CS-III: 2013 summer, CS-IV: 2014 summer. Category of roots was divided by their thickness. Thick root: $10-20 \mathrm{~mm}$ in diameter, Semi-thick root: $5-10 \mathrm{~mm}$, middle root: $2-5 \mathrm{~mm}$, fine root: $<2 \mathrm{~mm}$

from Tokyo 5 months after the accident (Takata et al. 2012d). The percentage of total radiocesium in fruits and leaves in peach trees from Tokyo 5 months after the accident was about 20\% (Takata et al. 2012d), while that value was $13 \%$ in peach trees from Fukushima 10 months after the accident in the present study (Fig. 9.4b). Though the sites of those two investigations were inconsistent with the amount of radiocesium fallout and the difference in the amount of fallout should have affected the distribution manner within the tree, the difference of the amount of ${ }^{137} \mathrm{Cs}$ in fruits and leaves between the fifth and tenth month may have been due to the effect of translocation of Cs. Tagami and Uchida (2016) suggested that ${ }^{137} \mathrm{Cs}$ in leaves is translocated to the tree body just before leaf fall in a study on cherry trees, which belongs to the same plant family as peach trees. Therefore, it is considered that cesium in leaves is translocated to the tree body just before leaf fall also in peach trees.

Figure 9.4a shows that the total amount of ${ }^{137} \mathrm{Cs}$ in trees was highest after 1 year and decreased in subsequent years. When looking at the year-over-year transition of each organ, ${ }^{137} \mathrm{Cs}$ in five and seven-year-old branches and stems decreased. The fiveyear-old branches were the youngest branches which received fallout, and the seven-year-old branches were the main branches at the time of the accident. There was no year-over-year transition of the distribution of ${ }^{137} \mathrm{Cs}$ in organs which did not 


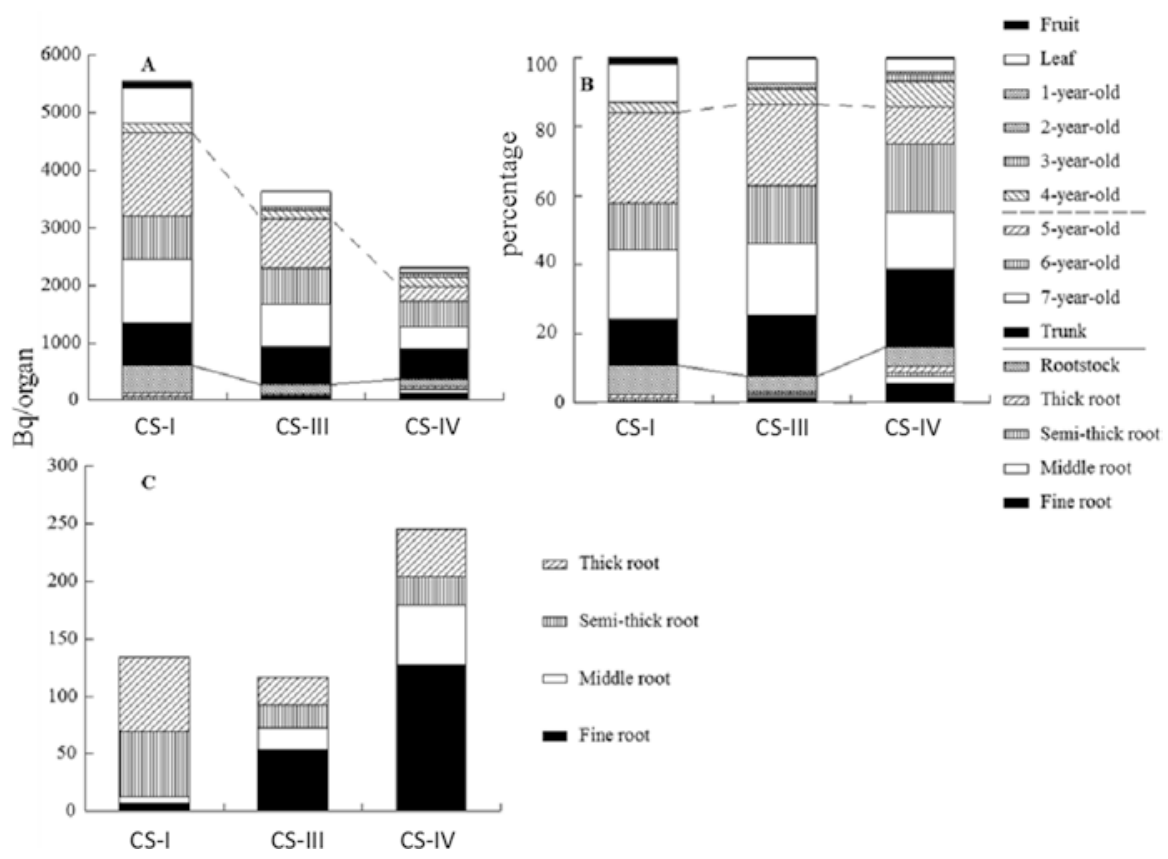

Fig. 9.4 Annual changes in ${ }^{137} \mathrm{Cs}$ content (A) and its distribution (percentage) (B) in peach trees after the Fukushima Daiichi Nuclear Power Plant Accident. Fig. 9.4C is an enlarged view of root ${ }^{137} \mathrm{Cs}$ content (Takata 2016. Organs above the dashed line grew after the accident. Branch age conforms to cropping season 4 (2014). CS: Cropping season after FDNPP accident, CS-I: 2011 summer, CS-III: 2013 summer, CS-IV: 2014 summer. Category of roots was divided by their thickness. Thick root: $10-20 \mathrm{~mm}$ in diameter, Semi-thick root: $5-10 \mathrm{~mm}$, middle root: $2-5 \mathrm{~mm}$, fine root: $<2 \mathrm{~mm}$

receive the fallout: that includes branches younger than 4 years old, fruit and leaves (Fig. 9.4b), though the percentage of ${ }^{137} \mathrm{Cs}$ which was transferred to fruit and leaves was $13.1 \%$ in the first year and decreased to $7.5 \%$ and $3.9 \%$ over the subsequent years. On the other hand, the distribution of ${ }^{137} \mathrm{Cs}$ increased year-over-year in the four-year-old branches, which developed in the year of the accident. This could be because branches accumulated radiocesium as they grew, while new leaves and fruits were produced every year. Also, it is considered that the source of Cs in newgrown organs were the stems, five-year-old and seven-year-old branches which decreased the amount of ${ }^{137} \mathrm{Cs}$ in them. However, five-year-old branches were pruned during winter and the cause of the decrease could be either the pruning or redistribution. Therefore, it is estimated that the source of ${ }^{137} \mathrm{Cs}$ in new-grown organs were the stems and seven-year-old branches, which were not pruned.

Although there was no general tendency in the transition of the amount of ${ }^{137} \mathrm{Cs}$ in the roots; the roots thinner than $5 \mathrm{~mm}$ and rootlets had higher amounts of ${ }^{137} \mathrm{Cs}$ year- over-year (Fig. 9.4c). Two reasons can be considered to explain this phenom- 


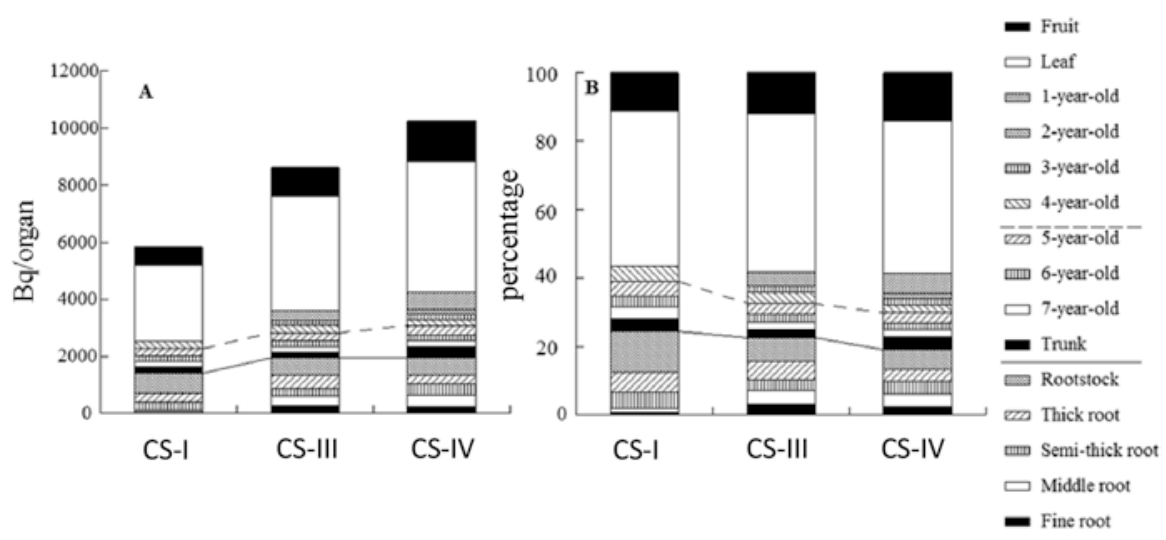

Fig. 9.5 Annual changes in ${ }^{40} \mathrm{~K}$ content (A) and its distribution (percentage) (B) in peach trees after the Fukushima Daiichi Nuclear Power plant Accident (Takata 2016. Organs above the dashed line grew after the accident. Branch age conforms to cropping season 4 (2014). CS: Cropping season after FDNPP accident, CS-I: 2011 summer, CS-III: 2013 summer, CS-IV: 2014 summer. Category of roots was divided by their thickness. Thick root: 10-20 mm in diameter, Semi-thick root: $5-10 \mathrm{~mm}$, middle root: $2-5 \mathrm{~mm}$, fine root: $<2 \mathrm{~mm}$

enon: (1) the absorption from the soil and (2) translocation from thick roots and terrestrial organs. However, as explained in an earlier section, radiocesium existed mainly in the surface horizon, especially to a depth of $5 \mathrm{~cm}$ rather than the lower horizons. Because the main root area of peach trees is deeper than the horizon, it is unrealistic that ${ }^{137} \mathrm{Cs}$ can be absorbed by the roots. Therefore, it is considered that translocation from thicker roots contributes to the increase in the amount of ${ }^{137} \mathrm{Cs}$ in medium and fine roots. The amount of ${ }^{137} \mathrm{Cs}$ in the trees decreased more than the estimated quantity removed by fruit, leaves and pruned branches (Fig. 9.3a). It is necessary to consider other possibilities to explain this result such as ${ }^{137} \mathrm{Cs}$ exudation from the surface of branches or roots and decay of rootlets. As mentioned earlier, a proportion of ${ }^{137} \mathrm{Cs}$ is translocated to newly grown fine roots, and these new roots often decay in a single season. Therefore, ${ }^{137} \mathrm{Cs}$ transferred to the soil by falling out or decay is not possibly negligible.

On the other hand, the total ${ }^{40} \mathrm{~K}$ in trees was smallest in the first year and increased with years; the increase in the fruit and leaves were considerable (Fig. 9.5). This result is closely related to the increase of weight of the trees (Fig. 9.3), and completely opposite to the year-over-year transition of ${ }^{137} \mathrm{Cs}$ which was mentioned earlier.

During the 4 years of the investigation after the accident, it was found that the absorption of radiocesium from soil was much smaller than derived from the tree. The source of ${ }^{137} \mathrm{Cs}$ in the fruits could be the stems and main branches, and the results show that ${ }^{137} \mathrm{Cs}$ transferred from the stems or branches to fruits was not supplemented by the soil. On the other hand, ${ }^{40} \mathrm{~K}$ is transported from the soil through the stems and main branches. It suggests that the dynamics of $\mathrm{Cs}$ and $\mathrm{K}$ in fruits trees is different. 


\subsection{The Current Investigation}

It is important to investigate the movement of ${ }^{137} \mathrm{Cs}$ in trees, but its concentration will become too low to investigate like ${ }^{134} \mathrm{Cs}$ when it reaches its half-life in the future. The dynamics of Cs need to be clarified in case a similar nuclear accident was to occur elsewhere in the world in the future. Although the dynamics of K, which is in the same group as $\mathrm{Cs}$, is sometimes compared to understand the dynamic of $\mathrm{Cs}$, it has been found that those dynamics are partially different in fruit trees. Therefore, the difference in the distribution of $\mathrm{Cs}$ and $\mathrm{K}$ in soil, absorption through roots, the transition from roots to terrestrial parts, and the transition rate from old to new organs can be obstacles to understanding the dynamics of Cs. Though comparing stable isotope ${ }^{133} \mathrm{Cs}$ is another method, there are several problems to its use as an alternative to ${ }^{137} \mathrm{Cs}$. The analysis using high precision equipment is necessary to measure ${ }^{133} \mathrm{Cs}$ in the natural environment though it is more abundant than ${ }^{137} \mathrm{Cs}$. Even if ${ }^{133} \mathrm{Cs}$ is added to the environment to make the measurement easier, its dynamics and concentration may be different than ${ }^{137} \mathrm{Cs}$. Also, even if ${ }^{133} \mathrm{Cs}$ was not added, the natural ${ }^{133} \mathrm{Cs}$ may show a different dynamic from ${ }^{137} \mathrm{Cs}$ because the natural ${ }^{133} \mathrm{Cs}$ concentration is much higher than ${ }^{137} \mathrm{Cs}$. A simultaneous measurement of ${ }^{133} \mathrm{Cs}$ and ${ }^{137} \mathrm{Cs}$ is essential to solve these problems and it should be performed before the concentration of ${ }^{137} \mathrm{Cs}$ becomes too low to measure. Now we found several results on the similarity and difference of dynamics and abundance between ${ }^{133} \mathrm{Cs}$ and ${ }^{137} \mathrm{Cs}$. For example, the transfer factor ratio of ${ }^{133} \mathrm{Cs}$ and ${ }^{137} \mathrm{Cs}$ to fruit is likely to be similar when they are applied at the same time to blueberries. Other experiments such as spraying with ${ }^{133} \mathrm{Cs}$ have been performed together with investigations using ${ }^{137} \mathrm{Cs}$. Also, the difference of dynamics of Cs which stored in terrestrial and subterranean tree parts has been analyzed.

Acknowledgments This article is based on the collaborative research with Dr. Eriko Yasunaga, Dr. Haruto Sasaki, Dr. Keitaro Tanoi, Dr. Natsuko I. Kobayashi, Dr. Seiichi Oshita (the University of Tokyo) and Mamoru Sato, Kazuhiro Abe (Fukushima Prefecture Agricultural Technology Centre), with the assistance of Mr. Kengo Izumi, Mr. Kenichiro Ichikawa (the University of Tokyo). This study was partly supported by of Ministry of agriculture, forestry and fisheries (MAFF, Japan).

\section{References}

Antonopoulos-Domis M, Clouvas A, Gagianas A (1990) Compartment model for long-term contamination prediction in deciduous fruit trees after a nuclear accident. Health Phys 58:737-741

Komatsu T (2014) Actual condition of sale and the trend of direct selling by fruit farm management after a nuclear hazard. Jpn J Farm Manage 52:47-52

Madoz-Escande C, Henner P, Bonhomme T (2004) Foliar contamination of Pharsalus vulgaris with aerosols of Cs-137, Sr-85, Ba-133 and Te-123m: influence of plant development stage upon contamination and rain. J Environ Radioact 73:49-71

National Statistics Center (2016) e-stat - FRUIT tree production and shipping statistics -. http:// www.e-stat.go.jp/SG1/estat/List.do?lid=000001160923 
Tagami K, Uchida S (2016) Seasonal change of radiocesium concentration in deciduous tree leaves. KEK Proc 17:72-76

Takata D (2016) Translocation of radiocerium in fruit trees. In: Nakanishi TM, Tanoi K (eds) Agricultural implications of the Fukushima nuclear accident -the first three years. Springer, Tokyo, pp 119-144

Takata D, Yasunaga E, Tanoi K, Nakanishi T, Sasaki H, Oshita S (2012a) Radioactivity distribution of the fruit trees ascribable to radioactive fall out: a study on stone fruits cultivated in low level radioactivity region. Radioisotopes 61:321-326 (in Japanese with English abstract and tables)

Takata D, Yasunaga E, Tanoi K, Nakanishi T, Sasaki H, Oshita S (2012b) Radioactivity distribution of the fruit trees ascribable to radioactive fall out (II): transfer of raiocaesium from soil in 2011 when Fukushima Daiichi nuclear power plant accident happened. Radioisotopes 61:517-521 (in Japanese with English abstract and tables)

Takata D, Yasunaga E, Tanoi K, Kobayashi N, Nakanishi T, Sasaki H, Oshita S (2012c) Radioactivity distribution of the fruit trees ascribable to radioactive fall out (III): a study on peach and grape cultivated in South Fukushima. Radioisotopes 61:601-606 (in Japanese with English abstract and tables)

Takata D, Yasunaga E, Tanoi K, Nakanishi T, Sasaki H, Oshita S (2012d) Radioactivity distribution of the fruit trees ascribable to radioactive fall out (IV): cesium content and its distribution in peach trees. Radioisotopes 61:607-612 (in Japanese with English abstract and tables)

Takata D, Sato M, Abe K, Yasunaga E, Tanoi K (2013a) Radioactivity distribution of the fruit trees ascribable to radioactive fall out (V): shifts of caesium-137 from scion to other organs in 'Kyoho' grapes. Radioisotopes 61:455-459 (in Japanese with English abstract and tables)

Takata D, Sato M, Abe K, Yasunaga E, Tanoi K (2013b) Radioactivity distribution of the fruit trees ascribable to radioactive fall out (VI): effect of heterogeneity of caesium-137 concentration in soil on transferability to grapes and fig trees. Radioisotopes 62:533-538 (in Japanese with English abstract and tables)

Takata D, Yasunaga E, Tanoi K, Nakanishi T, Sasaki H, Oshita S (2013c) Radioactivity distribution of the fruit trees ascribable to radioactive fall out (VII): seasonal changes in radioceasium of leaf, fruit and lateral branch in peach trees. Radioisotopes 62:539-544 (in Japanese with English abstract and tables)

Takata D, Sato M, Abe K, Tanoi K, Kobayashi N, Yasunaga E (2014) Shift of radiocaesium derived from Fukushima Daiichi Nuclear Power Plant accident in the Following Year in peach trees. In: 29th international horticultural congress, impact of Asia-Pacific horticulture 117, p 215

Takata D, Ichikawa K, Sato M, Abe K, Kobayashi N, Tanoi K, Yasunaga E (2016) Seasonal change of radiocesium concentration in deciduous tree leaves. The 17th workshop

Open Access This chapter is licensed under the terms of the Creative Commons Attribution 4.0 International License (http://creativecommons.org/licenses/by/4.0/), which permits use, sharing, adaptation, distribution and reproduction in any medium or format, as long as you give appropriate credit to the original author(s) and the source, provide a link to the Creative Commons license and indicate if changes were made.

The images or other third party material in this chapter are included in the chapter's Creative Commons license, unless indicated otherwise in a credit line to the material. If material is not included in the chapter's Creative Commons license and your intended use is not permitted by statutory regulation or exceeds the permitted use, you will need to obtain permission directly from the copyright holder.

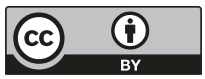

